\title{
вмJ Global Health Stuck in the middle: a systematic review of authorship in collaborative health research in Africa, 2014-2016
}

\author{
Bethany L Hedt-Gauthier (D) , ${ }^{1}$ Herve Momo Jeufack, ${ }^{2}$ Nicholas H Neufeld, ${ }^{3}$ \\ Atalay Alem, ${ }^{4}$ Sara Sauer, ${ }^{5}$ Jackline Odhiambo, ${ }^{6}$ Yap Boum (iD , ${ }^{7}$ \\ Miriam Shuchman, ${ }^{3}$ Jimmy Volmink ${ }^{8}$
}

To cite: Hedt-Gauthier BL, Jeufack HM, Neufeld NH, et al. Stuck in the middle: a systematic review of authorship in collaborative health research in Africa, 2014-2016. BMJ Global Health 2019;4:e01853. doi:10.1136/ bmjgh-2019-001853

Handling editor Seye Abimbola

- Additional material is published online only. To view please visit the journal online (http://dx.doi.org/10.1136/ bmjgh-2019-001853).

Received 18 July 2019 Revised 26 September 2019 Accepted 28 September 2019

Check for updates

(C) Author(s) (or their employer(s)) 2019. Re-use permitted under CC BY-NC. No commercial re-use. See rights and permissions. Published by BMJ.

For numbered affiliations see end of article.

\section{Correspondence to} Dr Bethany L Hedt-Gauthier; bethany_hedt@hms.harvard. edu

\section{ABSTRACT}

Background Collaborations are often a cornerstone of global health research. Power dynamics can shape if and how local researchers are included in manuscripts. This article investigates how international collaborations affect the representation of local authors, overall and in first and last author positions, in African health research.

Methods We extracted papers on 'health' in sub-Saharan Africa indexed in PubMed and published between 2014 and 2016. The author's affiliation was used to classify the individual as from the country of the paper's focus, from another African country, from Europe, from the USA/ Canada or from another locale. Authors classified as from the USA/Canada were further subclassified if the author was from a top US university. In primary analyses, individuals with multiple affiliations were presumed to be from a high-income country if they contained any affiliation from a high-income country. In sensitivity analyses, these individuals were presumed to be from an African country if they contained any affiliation an African country. Differences in paper characteristics and representation of local coauthors are compared by collaborative type using $\chi^{2}$ tests.

Results Of the 7100 articles identified, $68.3 \%$ included collaborators from the USA, Canada, Europe and/or another African country. $54.0 \%$ of all 43429 authors and $52.9 \%$ of 7100 first authors were from the country of the paper's focus. Representation dropped if any collaborators were from USA, Canada or Europe with the lowest representation for collaborators from top US universities-for these papers, $41.3 \%$ of all authors and $23.0 \%$ of first authors were from country of paper's focus. Local representation was highest with collaborators from another African country. $13.5 \%$ of all papers had no local coauthors. Discussion Individuals, institutions and funders from high-income countries should challenge persistent power differentials in global health research. South-South collaborations can help African researchers expand technical expertise while maintaining presence on the resulting research.

\section{INTRODUCTION}

Despite increases in African research-scientists in Africa more than doubled their

\section{Key questions}

\section{What is already known?}

- Global health research often relies on collaborations between institutions. Previous studies have noted underrepresentation of local coauthors in collaborative research, particularly in the prime first and last author positions.

What are the new findings?

- Collaborating with high-income country researchers decreases local representation, particularly in first and last positions, and the lowest representation $\mathrm{OC}$ curs when collaborating with individuals from a top US university.

- Collaborating with individuals from other African institutions increases local representation in resulting papers.

What do the new findings imply?

- The power dynamics within global health research collaborations must be addressed to increase inclusion and leadership of local authors.

- Investing in South-South partnerships could provide opportunities to increase technical resources for researchers while maintaining the individual's leadership of the resulting work.

publications in science, technology, engineering and math from 2003 to $2012^{1}$ - there is currently a great deficit in resources for African health research. Africa has only 198 researchers per million inhabitants, compared over 4000 in the UK and the $\mathrm{US}^{2}$ and no country in Africa has achieved the African Union goal of spending $1 \%$ of the gross domestic product on research and development. $^{2}{ }^{3}$ Less than $10 \%$ of global investments in health research is spent in developing countries, where more than $90 \%$ of preventable mortality occurs. ${ }^{4}$

In this context, researchers in low-income and middle-income countries (LMICs), and sub-Saharan Africa specifically, collaborate 
extensively with high-income country (HIC) researchers on local studies that may be vital to health and policy in their countries. ${ }^{56}$ Yet such collaborations can lead to reports of African data with no or very few local authors, meaning that 'the professional recognition and social capital that comes with publication" eludes the African contributors to those projects. These inequities undermine science and the careers of scientists from Africa. ${ }^{8}$

Several bibliometric analyses over the last decade have used authorship to quantify the equity of partnerships on papers about health in LMICs. While some of these articles report high levels of LMIC representation, ${ }^{9} 10$ most found that LMIC authors are profoundly underrepresented, representing less than $50 \%$ of first authors and in some cases, less than $50 \%$ of all authors. ${ }^{11-14}$ Some of these papers have shown that LMIC author representation decreases in the prime first or last positions compared with overall representation. ${ }^{15} 16$

We revisit this issue with a new lens-if collaborations with external colleagues are key for global health research, how do such collaborations drive overall authorship and publication structure? We focused on five different types of geographic collaborations that we identified a priori as being of interest, assessing authorship dynamics on papers that included collaborators from: (1) top ranking US universities, (2) the USA and Canada, (3) Europe, (4) other African countries and finally (5) a mixture of geographic locales outside of the country of the paper's focus. Here, we present results on how these collaborations affect inclusion of local authors, particularly in prime first or last authorship positions.

\section{METHODS}

\section{Identification of relevant articles}

We searched PubMed for articles that were published between 2014 and 2016 with the term 'health' in either the title or abstract and 'Africa South of the Sahara' indicated as a Medical Subject Heading (MeSH) term. We selected PubMed and this time period since PubMed began recording author affiliation data in 2014. The PubMed search results were downloaded in XML format. We then used Statistical Analysis System (SAS 9.4, University Edition) software and developed a custom algorithm to scrape and clean the XML file. This algorithm allowed for the extraction of the following data: title, abstract, key words, type of publication, author names, author order, author affiliations and journal names.

To determine whether the article was eligible for analyses, we developed a computer algorithm in Stata V.14 to search and record any country names captured in the title, objectives, methods, results, conclusion, key words and abstract. We also searched for prominent city names or region/province names and linked these to the appropriate country. Extracted articles were removed from the database for the following reasons: no country was named in any of the searched domains or none of the named countries were located in sub-Saharan Africa

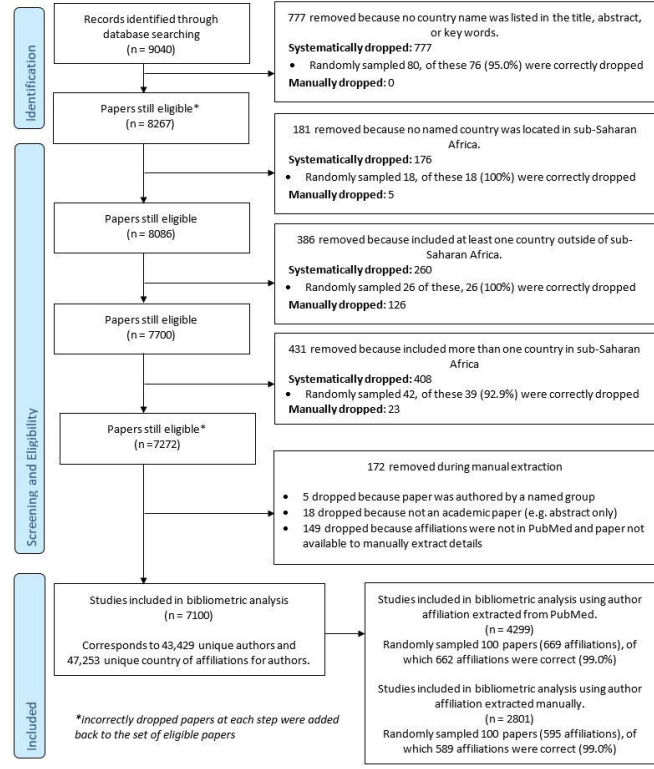

Figure 1 Process of identifying eligible papers and author affiliations for bibliometric analysis of African health research, 2014-2016.

(considered countries and regional groupings are listed in the online supplementary appendix). In our analysis, we included only articles that focused on a single country and so papers that had multiple countries identified in the searched domains were also removed from the database. For each step of systematic removal of articles, we randomly sampled $10 \%$ of the removed articles to confirm ineligibility (reported in figure 1). In the processes of reviewing the subset of articles that required manual collection of author affiliation details or during data cleaning, we identified an additional 326 papers that did not meet eligibility criteria and were therefore removed from our dataset. For quality assessment, we also sampled 200 papers included in the final dataset to confirm eligibility for inclusion and author affiliations for those papers (figure 1).

\section{Classification of author affiliations and paper collaboration types}

For eligible papers, we used a computer algorithm to search author affiliations to determine the country(s) of the author's affiliation. If the affiliation field was missing for any author or if we detected errors in the extracted affiliations-most notably, cases in which the corresponding author's affiliation was assigned to all authors on the paper or cases in which the affiliations of all authors on the paper were assigned to each of the authors-the paper was reviewed and relevant details were manually entered into a Microsoft Access database. This database was merged with the primary database. At this stage, some additional papers that were not accessible online or through requests to the corresponding author were removed (figure 1).

For the final dataset, we classified both authors and papers. We classified each author as being primarily 


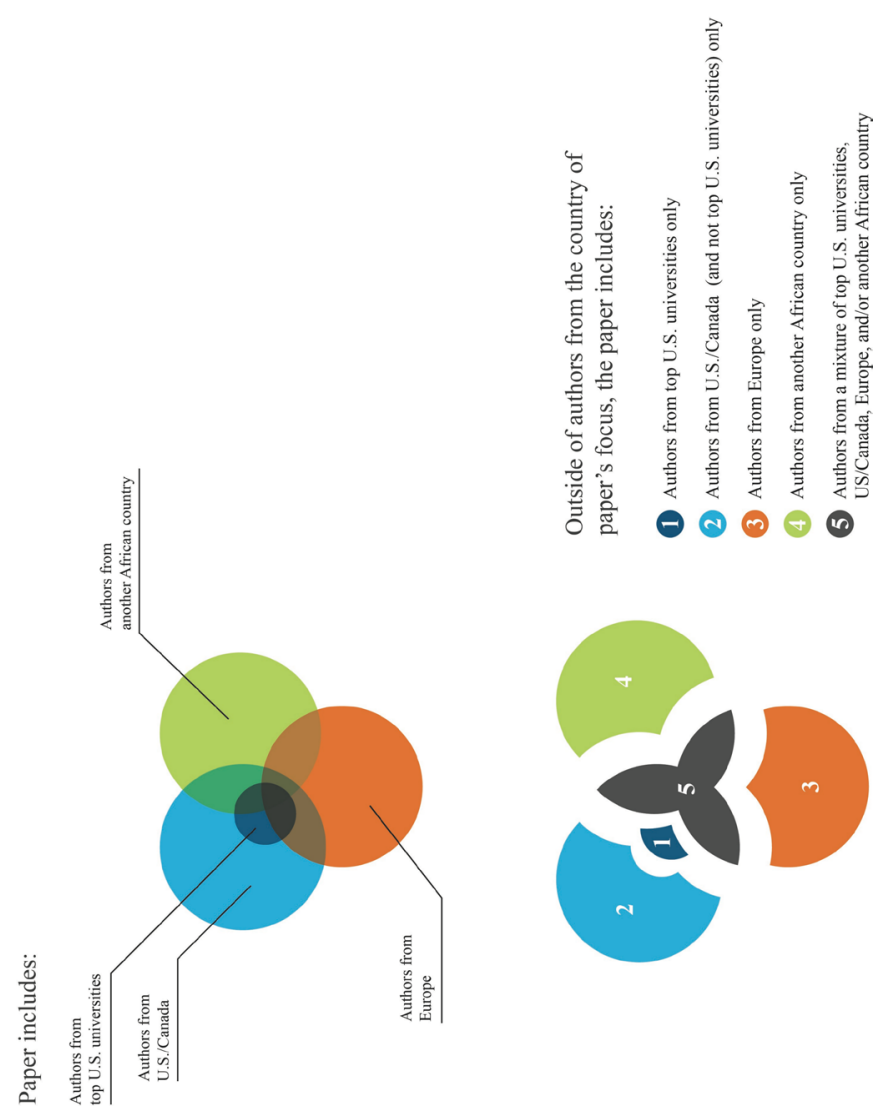

Figure 2 Definition of collaboration types considered in bibliometric analyses of authorship on publications about health in Africa, 2014-2016.

affiliated with (1) the same country as the paper's focus, (2) another African country, (3) the USA, Canada or Europe or (4) another country not yet classified (North Africa, Asia, Australasia or South America). If an author had multiple countries associated with their affiliations, we used the following logic: (1) If any affiliation country was the USA, Canada or Europe, then the author was classified as being primarily affiliated with the USA, Canada or Europe. (2) If not, if any affiliation country was the same country as the paper's focus, the author was classified as being primarily affiliated with that country. (3) If not, if any affiliation was another African country, the author was classified as being primarily affiliated with another African country. (4) Finally, any author remaining unclassified was considered to be primarily affiliated with another country not yet classified. By this logic, affiliations located in the USA, Canada or Europe overrode affiliations located in the same country as the paper's focus. (For example, author BHG often has USA and Rwanda affiliations, and in this classification, she would be classified as being from the USA.) In a sensitivity analysis, we reversed the logic so that affiliations located in the country of the paper's focus and affiliations with other African countries overrode affiliations with the USA, Canada or Europe. (Here, author BHG would be classified as being from Rwanda.)
We classified papers into one of five geographic collaborative types. For the first four types, we looked at: (1) papers that included any authors from a top US university; (2) paper included any authors from the USA or Canada; (3) paper included any authors from Europe and (4) paper included any authors from an African institution outside of the country of the paper's focus (figure 2). To disentangle the effects of each collaborative type on each other, we created categories with no overlap between these groups and then added fifth collaborative category, namely papers that included collaborators from multiple geographies outside of the country of the paper's focus. While for author-level analyses, authors with multiple affiliations are classified as having a single locale as described above, in paper collaboration type, we allowed all affiliations for each author to contribute to determination of paper collaborative type. To identify authors from a top US university, we used affiliation with one of the top 20 US graduate schools of public health, as identified by the 2015 US News and World Report rankings, ${ }^{17}$ as a proxy. An author with any affiliation with a university on this list was classified as being from a top US university, regardless of whether the author was at the school of public health-for example, since Harvard Chan School was on the 2015 US News and World Report top 20 list, any author with a Harvard-affiliation, such as an affiliation with Harvard Medical School, would be categorised as being from a top US university. The schools included were: Boston University, Columbia University, Emory University, George Washington University, Harvard University, Johns Hopkins University, Ohio State University, Tulane University, University of Alabama at Birmingham, University of California at Berkeley, University of California at Los Angeles, University of Illinois at Chicago, University of Iowa, University of Michigan at Ann Arbour, University of Minnesota at Twin Cities, University of North Carolina at Chapel Hill, University of Pittsburgh, University of South Florida, University of Washington and Yale University.

\section{Analyses}

We describe paper characteristics, including the region of the paper's focus, whether the paper is a single-author or multiauthor paper, the disease area of focus, the journal's coverage (an African national, an African regional journal or an international journal), the journal's impact factor and the paper's collaborative type. We identified the paper's disease area by searching the title, abstract and keywords for disease areas identified in Chapter 4 of the 2014 African Regional Health Report ${ }^{18}$ HIV/AIDS; tuberculosis; malaria; epidemic/pandemic prone diseases (cholera, Ebola, Marburg, influenza, yellow fever, meningococcal meningitis, Lassa fever, polio); neglected tropical diseases (lymphatic filariasis, helminthiasis, trachoma, schistosomiasis, onchocerciasis, dracunculiasis, yaws, leprosy, trypanosomiasis, Buruli ulcer and leishmaniasis); non-communicable diseases (cardiovascular disease, chronic respiratory disease, 
diabetes); cancer; sickle cell disease; mental and neurological disorders (mental illness, mental disorder, depression, psychiatric disorder) and road traffic injuries. It is possible for papers to have more than one disease area categorisation and for some papers, the paper's focus was outside of the disease areas covered by the 2014 African Regional Health Report. We extracted the 2016 impact factor listed on journal websites. If no impact factor was listed on the website or if the impact factor listed was not from 2016, we used the impact factor listed in the Journal Citation Reports (Clarivate Analytics 2017). If the Journal Citation Reports also did not have the 2016 impact factor, the most recent available impact factor was used. If impact factor was not reported on the journal's website or in Journal Citation Reports, it was listed as 'not available'. We assess the relationship between the paper characteristics and collaborative type using $\chi^{2}$ tests.

We present the per cent of authors classified as being from the country of the paper's focus, overall and stratified by authorship position (first, last and middle). We base authorship positions on the author order, with first authors being the first name listed and last authors being the last name listed. We did not account for multiple first or last authors as this information is not currently captured in PubMed. For papers with a single author, we counted that author as the first author and did not report a last author for that paper. For all analyses, we present overall paper and author trends stratified by the paper's geographic collaboration type. We also report the per cent of papers that have no authors from the country of the paper's focus, overall and stratified by collaborative type. We compare results across collaborative types using a $\chi^{2}$ tests. All analyses were conducted in Stata V.14.1. The datasets generated during and/or analysed during the current study are available from the corresponding author on reasonable request.

\section{Patient and public involvement}

Neither patients nor the public were involved in this research.

\section{RESULTS}

\section{Description of included papers}

Our initial search yielded 9040 articles, and after applying the various exclusion criteria, yielded a final database of 7100 health research papers focused on a single sub-Saharan African country, corresponding to 43429 authors (figure 1). Of these authors, 3574 had two or more countries of affiliation. For the papers included, 4299 papers had author affiliation details based on data extracted from PubMed and 2801 had author affiliation details manually extracted. Error rates were less than $7 \%$ at all validation steps (figure 1 ).

Figure 3 maps, by country, the number of papers, the per cent of papers with at least one local author and the per cent of papers with a local first and/or last author (numbers provided in the online supplementary appendix). The largest proportion of papers were from East Africa $(\mathrm{n}=3092,43.6 \%)$, followed by West Africa ( $\mathrm{n}=2045,28.8 \%)$ (table 1). A small fraction of papers $(\mathrm{n}=281,4.0 \%)$ had only a single author. A fifth of papers $(\mathrm{n}=1455)$ were related to HIV/AIDS and very few $(n=22,0.3 \%)$ to sickle-cell disease. The majority of papers $(\mathrm{n}=6331,89.2 \%)$ were published in international journals, most in journals with an impact factor between 1 to $2.5(\mathrm{n}=3104,43.7 \%)$ or 2.5 to $4(\mathrm{n}=2017,28.4 \%)$.

\section{Authorship structure by geographic collaboration type}

Of the 7100 papers, 4846 (68.3\%) had an author from either the USA, Canada, Europe or another African country outside of the country of the paper's focus. Of all papers, 1192 (16.8\%) had authors with an affiliation with a top US university, 2617 (36.9\%) had an author from the USA/Canada with 1425 (54.5\%) of these having no author with an affiliation with a top US university, 2620 $(36.9 \%)$ had an author from Europe and $879(12.4 \%)$ had an author from another African country outside of the country of the paper's focus. For the non-overlapping collaborative categories (figure 2), $830(11.7 \%)$ of all papers had collaborators from top US universities only,

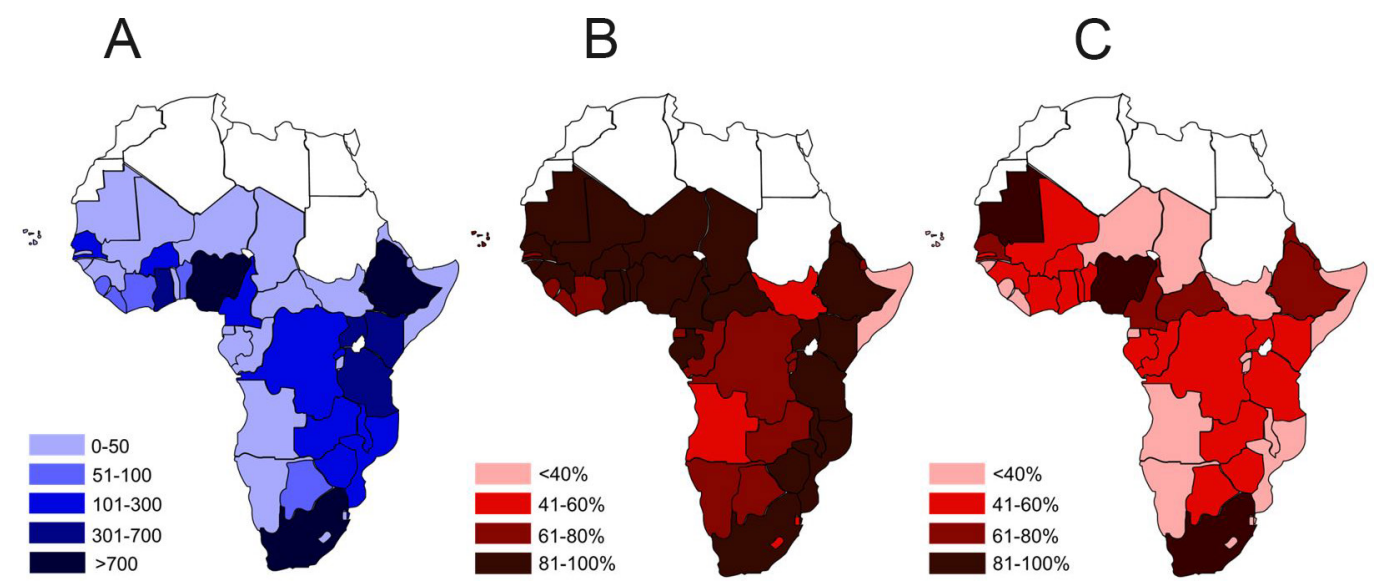

Figure 3 Geographic distribution of African health research papers and local authors between 2014-2016. (A) shows distribution of number of papers, (B) shows per cent of papers with at least one coauthor from the country of the paper's focus and $(\mathrm{C})$ shows per cent of papers with first and/or last author from the country of the paper's focus. 
Table 1 Description of papers included in systematic review of health research in Africa, 2014-2016

\begin{tabular}{|c|c|c|}
\hline & \multicolumn{2}{|c|}{$n=7100$} \\
\hline & $\mathbf{N}$ & $\%$ \\
\hline \multicolumn{3}{|l|}{ Region of paper's focus } \\
\hline Central Africa & 391 & 5.5 \\
\hline East Africa & 3092 & 43.6 \\
\hline Southern Africa & 1572 & 22.1 \\
\hline West Africa & 2045 & 28.8 \\
\hline \multicolumn{3}{|l|}{ Number of authors on paper } \\
\hline Single author & 281 & 4.0 \\
\hline Multiple authors & 6819 & 96.0 \\
\hline \multicolumn{3}{|l|}{ Disease area* $^{*}$} \\
\hline HIV/AIDS & 1455 & 20.5 \\
\hline Tuberculosis & 395 & 5.6 \\
\hline Malaria & 632 & 8.9 \\
\hline $\begin{array}{l}\text { Epidemic/pandemic prone } \\
\text { diseases }\end{array}$ & 278 & 3.9 \\
\hline Neglected tropical diseases & 213 & 3.0 \\
\hline Non-communicable diseases & 277 & 3.9 \\
\hline Cancer & 169 & 2.4 \\
\hline Sickle-cell disease & 22 & 0.3 \\
\hline Mental and neurological disorders & 396 & 5.6 \\
\hline Road traffic injuries & 68 & 1.0 \\
\hline \multicolumn{3}{|l|}{ Journal coverage } \\
\hline African, National & 272 & 3.8 \\
\hline African, Regional & 497 & 7.0 \\
\hline International & 6331 & 89.2 \\
\hline \multicolumn{3}{|l|}{ Journal's 2015 impact factor } \\
\hline No impact factor & 871 & 12.3 \\
\hline Less than 1 & 533 & 7.5 \\
\hline $1-2.5$ & 3104 & 43.7 \\
\hline $2.5-4$ & 2017 & 28.4 \\
\hline $4-10$ & 409 & 5.8 \\
\hline Greater than 10 & 166 & 2.3 \\
\hline \multicolumn{3}{|l|}{ Paper's collaborative type } \\
\hline Only authors from country of focus & 2254 & 31.8 \\
\hline $\begin{array}{l}\text { Authors include individuals from } \\
\text { top US university (only) }\end{array}$ & 830 & 11.7 \\
\hline $\begin{array}{l}\text { Authors include individuals from } \\
\text { USA/Canada but not top US } \\
\text { university (only) }\end{array}$ & 916 & 12.9 \\
\hline $\begin{array}{l}\text { Authors include individuals from } \\
\text { Europe (only) }\end{array}$ & 1665 & 23.5 \\
\hline $\begin{array}{l}\text { Authors include individuals from } \\
\text { other African countries (only) }\end{array}$ & 303 & 4.3 \\
\hline $\begin{array}{l}\text { Authors include individuals from } \\
\text { multiple outside locales }\end{array}$ & 1132 & \\
\hline
\end{tabular}

*Note, it is possible for a paper to have more than one area of focus or to cover a topic not captured on this list.
$916(12.9 \%)$ had collaborators from the USA/Canada only (excluding papers with collaborators from top US universities), 1665 (23.5\%) had collaborators from Europe only, $303(4.3 \%)$ had collaborators from other African countries only and $1132(15.9 \%)$ had collaborators from multiple regional locales outside of the country of the paper's focus.

Types of research produced (table 2): Geographic collaboration type was significantly associated with all assessed paper characteristics. Papers from Southern and West Africa and single author papers were significantly more likely to be authored exclusively by local authors (39.1\% of Southern Africa papers, $38.4 \%$ of West Africa papers, $\mathrm{p}<0.001 ; 49.8 \%$ of single author papers vs $31.0 \%$ of multiple author papers, $\mathrm{p}<0.001)$. Papers published in African journals were more likely to only have local coauthors or to have coauthors from another African institution only, whereas the proportion of those papers with authors from a top US university, the USA/Canada only or Europe only were significantly lower as compared with those published in international journals $(p<0.001)$. Over half of the papers $(60.6 \%)$ published in journals without impact factors were written with local coauthors only, compared with $4.8 \%$ of papers published in journals with an impact factor over $10(\mathrm{p}<0.001)$.

Structure of authors' positions (figure 4): Overall, $54.0 \%$ $(\mathrm{n}=23444$ of 43429$)$ of authors were from the same country as the paper's focus; this included $52.9 \%$ ( $\mathrm{n}=3753$ out of 7100) of first authors, 56.2\% ( $\mathrm{n}=16569$ out of 29 510 ) of middle authors and $45.8 \%$ ( $n=3122$ out of 6819 ) of last authors. The per cent of authors from the same country as the paper's focus decreased if any authors are affiliated with a top US university $(41.3 \%, \mathrm{n}=2506$ out of $6075)$; the USA/Canada (excluding top US universities) (47.0\%, $\mathrm{n}=2730$ out of 5803$)$; Europe $(43.5 \%, \mathrm{n}=4497$ out of 10332$)$ or from multiple locales $(35.9 \%, n=3593$ out of 10 006). This decrease was most pronounced in the first author position-from $52.9 \%$ overall to $23.0 \%$ $(\mathrm{n}=191$ out of 830$)$-if any authors were affiliated with a top US university. Representation of authors from the same country as the paper's focus, overall and in the prime positions, was highest, if the collaborators were from another African country at $64.9 \%$ for overall representation ( $\mathrm{n}=988$ out of 1523 authors), $65.0 \%$ ( $\mathrm{n}=197$ out of 303) for first authors and $43.8 \%$ ( $n=128$ out of 292) for last author positions. Representation of local authors was significantly different by collaborative type across all authorship positions ( $\mathrm{p}<0.01$ for all comparisons). Trends hold in the sensitivity analysis (figure 4B).

\section{Papers without any authors from the country of focus}

Overall, $13.5 \%$ ( $\mathrm{n}=958$ out of 7100 ) of papers had no authors from the country of focus and every country included in this analysis had some papers with no local representation, ranging from $5.7 \%$ of papers from South Africa ( $n=63$ out of 1097 ) to $68.4 \%$ of papers from Somalia ( $\mathrm{n}=13$ out of 19) (figure 3B, online supplementary appendix 1). The per cent of papers with no authors 


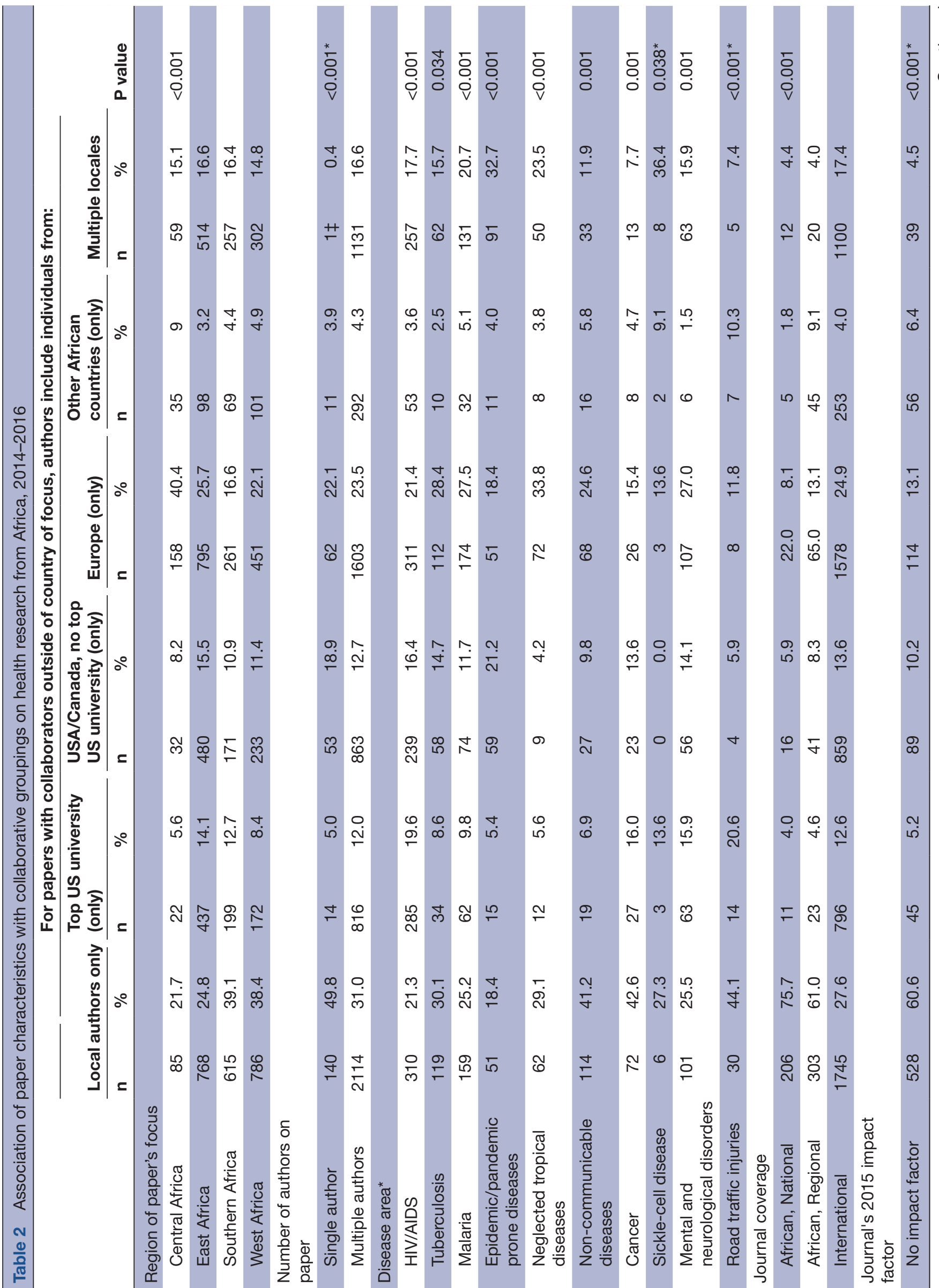

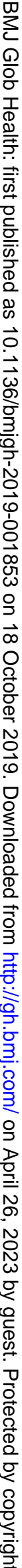



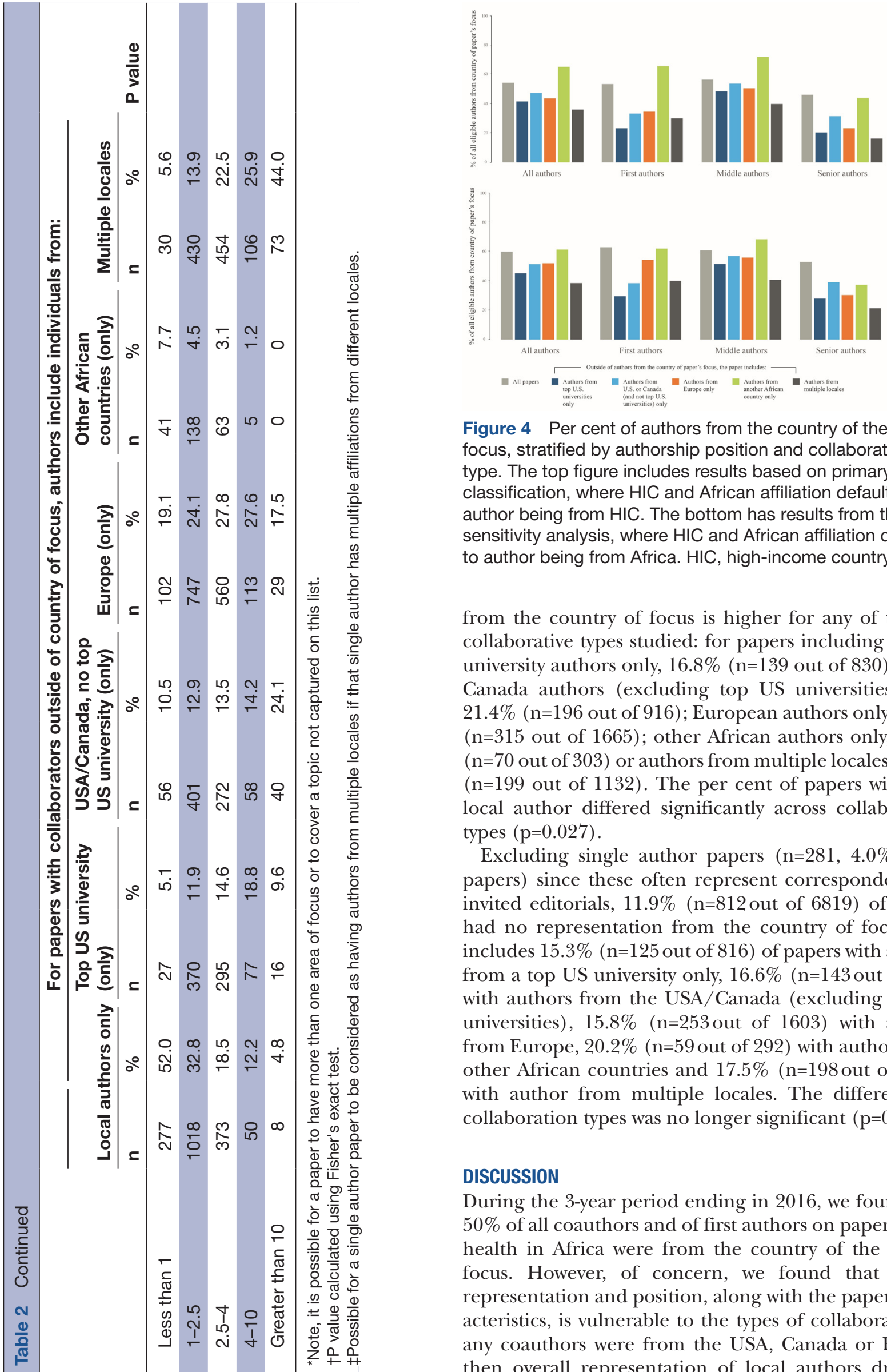

Figure 4 Per cent of authors from the country of the paper's focus, stratified by authorship position and collaboration type. The top figure includes results based on primary classification, where $\mathrm{HIC}$ and African affiliation defaults to author being from HIC. The bottom has results from the sensitivity analysis, where HIC and African affiliation defaults to author being from Africa. HIC, high-income country.

from the country of focus is higher for any of the five collaborative types studied: for papers including top US university authors only, $16.8 \%$ ( $\mathrm{n}=139$ out of 830 ); USA/ Canada authors (excluding top US universities) only, 21.4\% ( $\mathrm{n}=196$ out of 916 ); European authors only, $18.9 \%$ $(\mathrm{n}=315$ out of 1665$)$; other African authors only, $23.1 \%$ ( $n=70$ out of 303 ) or authors from multiple locales, $17.6 \%$ $(n=199$ out of 1132). The per cent of papers without a local author differed significantly across collaboration types $(\mathrm{p}=0.027)$.

Excluding single author papers $(n=281,4.0 \%$ of all papers) since these often represent correspondence or invited editorials, $11.9 \% \quad(\mathrm{n}=812$ out of 6819$)$ of papers had no representation from the country of focus; this includes $15.3 \%$ ( $\mathrm{n}=125$ out of 816 ) of papers with authors from a top US university only, $16.6 \%$ ( $n=143$ out of 863 ) with authors from the USA/Canada (excluding top US universities), $15.8 \%$ ( $\mathrm{n}=253$ out of 1603) with authors from Europe, 20.2\% ( $\mathrm{n}=59$ out of 292) with authors from other African countries and $17.5 \% \quad(\mathrm{n}=198$ out of 1131) with author from multiple locales. The difference by collaboration types was no longer significant $(\mathrm{p}=0.272)$.

\section{DISCUSSION}

During the 3-year period ending in 2016, we found over $50 \%$ of all coauthors and of first authors on papers about health in Africa were from the country of the paper's focus. However, of concern, we found that author representation and position, along with the paper's characteristics, is vulnerable to the types of collaboration. If any coauthors were from the USA, Canada or Europe, then overall representation of local authors dropped, 
particularly in the prime first and last author positions. This was most frequent when collaborators were from a top US university or from multiple locales. These results are supported by other analyses that show that researchers from the poorest countries are less likely to be in prominent author positions when engaged in international collaborations ${ }^{6}$ that papers with HIC last authors are significantly less likely to have LMIC first authors ${ }^{11}$ and that US-funded clinical trials are less likely to have LMIC authors in first or last positions. ${ }^{12}$ We also found that over one in eight publications including coauthors from the USA, Canada or Europe had no coauthors from the country of the paper's focus, showing that publishing 'about Africa without Africa' remains an ongoing issue despite longstanding efforts to call attention to it. ${ }^{19-21}$

Several factors may explain our findings. HIC investigators may be more likely to do the work of a first or last author, such as writing the first draft of a paper or overseeing the research (often remotely), because they have technical advantages over their LMIC counterparts. Many African countries have nascent research infrastructures and university training programme, limiting the number of qualified collaborators to lead projects. Beyond technical skills, HIC researchers typically have greater economic and academic resources including extensive institutional infrastructure to lead project administration; stronger and deeper research networks, including greater representation on journal editorial boards and more 'cultural capital' in the forms of accepted credentials and styles of speech. ${ }^{22} 23$

Taken together, these advantages give HIC partners a greater chance at prime authorship along with more control over the nature of the collaboration; yet there are several ways to equalise the playing field. HIC researchers and their institutions could create more opportunities for local collaborators to contribute in ways that lead to prime authorship. ${ }^{24}$ Further, there are calls for HIC researchers to invest in the individual and institutional capacity building of their partners, ${ }^{25}$ including investments in skills that promote their leadership of research endeavours. ${ }^{26}$ HIC institutions could incentivise African research leadership by changing their promotion poli$\operatorname{cies}^{22} 27$ and funders could look at African leadership and partners' investments in building capacity during the grant selection process. ${ }^{28-30}$ Further, others have suggested changing the current norms of authorship or how they are applied, ${ }^{31-34}$ moves that would recognise the more diverse roles often taken by LMIC partners or remove pressures to exclude collaborators due to the rewards inherent to authorship.

African scientists might also pursue an equity agenda by turning down some collaborations and seeking others. An interesting finding from our analyses is that Africa-based researchers may more readily hold a prime authorship position if they engage in South-South collaborations with researchers from other African countries. Similar to others, ${ }^{35-38}$ we found that intra-African collaborations produced a small fraction of the health research in Africa, and of these, South African researchers were the most common collaborative partner. ${ }^{35} 39$ Beyond the benefit of local representation in first and last authorship positions, these collaborations likely focus on research priorities of the region. ${ }^{40}$ However, there are distinct consequences, as papers resulting from intra-African collaborations are less likely to be cited ${ }^{38}$ and established collaborations outside of Africa is a significant predictor of an African scientist's productivity. ${ }^{41}$

This paper is subject to several limitations that should be noted when interpreting the results. First, we recognise that the data extraction process, the application of inclusion/exclusion criteria, and the process of determining where an author is from, are all subject to errors. The extraction process excluded articles published in non-indexed journals, which includes many national or regional African journals; this likely decreases the overall representation of local authors and papers collaborating with researchers from other Africa countries. However, given that collaborators from Africa were significantly less likely to publish in these types of journals, the overall effect of collaborations with researchers outside of Africa on inclusion of local authors is not likely to be affected. Further, the requirement of the word 'health' likely excluded non-English articles. We note that local and non-English journals provide important forums for publishing local research ${ }^{42}$ and that local authors are more likely to be engaged in these publications. We did validate all major steps of exclusion of this process, and the error rates were low. Further, we conducted a sensitivity analysis changing how author's country was classified based on affiliation and all trends persisted.

A final limitation is the focus on top US universities instead of premier institutions in other HICs and how the top US universities were identified. We chose to focus on the US institutions because of the noted "publish or perish' culture, but recognise that the issues elucidated in this paper may present at top institutions in Canada, Europe and elsewhere. Further, other university ranking systems could have been used to identify authors affiliated with a top US university; the use of the US News and World report list provides at minimum a proxy for general trends.

While authorship alone does not ensure that collaborations are inclusive and equitable, authorship is an important indicator for who is benefiting from research endeavours. Under the current system, researchers from sub-Saharan countries are underrepresented in prime authorship positions in health-related literature about their own countries and our data suggest that collaborations between researchers in sub-Saharan Africa and academics from HICs may perpetuate this situation, particularly when the HIC collaborators hold posts at top US universities. Our data also show that a significant fraction of papers about an African country have no coauthors from that country.

Additional scholarship is needed to identify the specific features of North-South collaborative research that could 
be blocking skilled African researchers from authorship entirely or locking them into middle authorship. Further, this scholarship must be coupled with open debates about how to shift these dynamics, including open discussions on the presence and consequence of inequities in global health collaborations. ${ }^{43-45}$ Only by fully understanding the basis for these inequities can the various parties involved-sponsors, journals, HIC and LMIC researchers and their institutions and governments-take the necessary steps to raise the stature of research collaborators in LMICs to true partners.

\author{
Author affiliations \\ ${ }^{1}$ Department of Global Health and Social Medicine, Harvard Medical School, Boston, \\ Massachusetts, USA \\ ${ }^{2}$ Accenture Toronto, Toronto, Ontario, Canada \\ ${ }^{3}$ Department of Psychiatry, Faculty of Medicine, University of Toronto, Toronto, \\ Ontario, Canada \\ ${ }^{4}$ Department of Psychiatry, School of Medicine, College of Health Sciences, Addis \\ Ababa University, Addis Ababa, Ethiopia \\ ${ }^{5}$ Department of Biostatistics, Harvard University T H Chan School of Public Health, \\ Boston, Massachusetts, USA \\ ${ }^{6}$ Partners In Health, Boston, MA, United States \\ ${ }^{7}$ Epicentre, Médecins Sans Frontières, Yaoundé, Cameroon \\ ${ }^{8}$ Department of Global Health and Dean's Office, Faculty of Medicine and Health \\ Sciences, Stellenbosch University, Stellenbosch, South Africa
}

Twitter Bethany L Hedt-Gauthier @BHedtGauthier and Yap Boum @yap.boum2

\begin{abstract}
Acknowledgements We acknowledge the important contributions of Teena Cherian and John Kearney in the preparation of data and manuscript and Alek Glasgard in the preparation of figures.
\end{abstract}

Contributors BH-G, HMJ, NN, MS and JV conceived the idea for this paper. HMJ and NN carried out data extraction and SS and JO conducted data cleaning. AA and $Y B$ supported data interpretation. All authors provided overview of analysis, supported manuscript writing and read and approved the final draft of the manuscript.

Funding The authors received no additional funding for this work.

Competing interests None declared.

Patient consent for publication Not required.

Provenance and peer review Not commissioned; externally peer reviewed.

Data availability statement Data are available on reasonable request.

Open access This is an open access article distributed in accordance with the Creative Commons Attribution Non Commercial (CC BY-NC 4.0) license, which permits others to distribute, remix, adapt, build upon this work non-commercially, and license their derivative works on different terms, provided the original work is properly cited, appropriate credit is given, any changes made indicated, and the use is non-commercial. See: http://creativecommons.org/licenses/by-nc/4.0/.

\section{ORCID iDs}

Bethany L Hedt-Gauthier http://orcid.org/0000-0002-9689-5413

Yap Boum http://orcid.org/0000-0002-6823-8539

\section{REFERENCES}

1 World Bank Group. A decade of development in sub-Saharan African science, technology, engineering \& mathematics research. Elsevier, 2014.

2 Simpkin V, Namubiru-Mwaura E, Clarke L, et al. Investing in health R\&D: where we are, what limits us, and how to make progress in Africa. BMJ Glob Health 2019;4.

3 Konde V. Towards achieving the African Union's recommendation of expenditure of $1 \%$ of GDP on research and development. ECA policy brief, No. ECA/18/004. United Nations Economic Commission for Africa, 2018.

4 Viergever RF. The mismatch between the health research and development (R\&D) that is needed and the R\&D that is undertaken: an overview of the problem, the causes, and solutions. Glob Health Action 2013;6:22450.

5 Jacobsen KH. Patterns of co-authorship in international epidemiology. Journal of Epidemiology \& Community Health 2009;63:665-9.

6 González-Alcaide G, Park J, Huamaní C, et al. Dominance and leadership in research activities: collaboration between countries of differing human development is reflected through authorship order and designation as corresponding authors in scientific publications. PLoS One 2017;12:e0182513.

7 Crane J. Scrambling for Africa: AIDS, expertise and the rise of American global health science. 1st edn. Ithaca: Cornell University Press, 2013.

8 Fourie C. The trouble with inequalities in global health partnerships: an ethical assessment. MAT 2018;5:155-55.

9 Chersich M, Blaauw D, Dumbaugh M, et al. Mapping of research on maternal health interventions in low- and middle-income countries: a review of 2292 publications between 2000 and 2012. Global Health 2016;12.

10 Plaisant A, Pierard C, Beyers N, et al. Authorship affiliations in original articles submitted to the International Journal of tuberculosis and lung disease. Int J Tuberc Lung Dis 2010;14:1650-2.

11 Schneider H, Maleka N. Patterns of authorship on community health workers in low-and-middle-income countries: an analysis of publications (2012-2016). BMJ Glob Health 2018;3:e000797.

12 Kelaher M, Ng L, Knight K, et al. Equity in global health research in the new millennium: trends in first-authorship for randomized controlled trials among low- and middle-income country researchers 1990-2013. Int J Epidemiol 2016;45:2174-83.

13 lyer AR. Authorship trends in the Lancet global health. The Lancet Global Health 2018;6:e142.

14 Adedokun BO, Olopade CO, Olopade OI. Building local capacity for genomics research in Africa: recommendations from analysis of publications in sub-Saharan Africa from 2004 to 2013. Glob Health Action 2016;9:31026.

15 Rees CA, Lukolyo H, Keating EM, et al. Authorship in paediatric research conducted in low- and middle-income countries: parity or parasitism? Trop Med Int Health 2017;22:1362-70.

16 Cash-Gibson L, Rojas-Gualdrón DF, Pericàs JM, et al. Inequalities in global health inequalities research: a 50-year bibliometric analysis (1966-2015). PLoS One 2018;13:e0191901.

17 US News. Best graduate public health schools, 2015. Available: https://www.usnews.com/best-graduate-schools/top-healthschools/public-health-rankings [Accessed 14 Mar 2018].

18 World Health Organization. The health of the people: What works The African Regional Health Report 2014. World Health Organization Regional Office for Africa, 2014.

19 Volmink J, Dare L. Addressing inequalities in research capacity in Africa. BMJ 2005;331:705-6.

20 Shuchman M, Wondimagegn D, Pain C, et al. Partnering with local scientists should be mandatory. Nat Med 2014;20:12.

21 The Lancet Global Health. Closing the door on parachutes and parasites. Lancet Glob Health 2018;6:e593.

22 Boum II Y, Burns BF, Siedner M, et al. Advancing equitable global health research partnerships in Africa. BMJ Glob Health 2018;3.

23 Shiffman J. Global health as a field of power relations: a response to recent commentaries. Int J Health Policy Manag 2015;4:497-9.

24 Hedt-Gauthier BL, Riviello R, Nkurunziza T, et al. Growing research in global surgery with an eye towards equity. $\mathrm{Br} J$ Surg 2019;106:e151-5.

25 Manabe YC, Jacob ST, Thomas D, et al. Resurrecting the triple threat: academic social responsibility in the context of global health research. Clin Infect Dis 2009;48:1420-2.

26 Airhihenbuwa CO, Ogedegbe G, Iwelunmor J, et al. Claim your space: leadership development as a research capacity building goal in global health. Health Educ Behav 2016;43:17S-24.

27 Hedt-Gauthier B, Airhihenbuwa CO, Bawah AA, et al. Academic promotion policies and equity in global health collaborations. The Lancet 2018;392:1607-9.

28 Zumla A, Makanga M, Nyirenda T, et al. Genesis of EDCTP2. Lancet Infect Dis 2015:15:11-13.

29 Lebel J, McLean R. A better measure of research from the global South. Nature 2018;559:23-6.

30 Hedt-Gauthier BL, Chilengi R, Jackson E, et al. With input from the AHI PHIT partnership collaborative. research capacity building integrated into PHIT projects: Leveraging research and research funding to build national capacity. BMC Health Services Research 2017; $17: 825$.

31 Zachariah R, Reid T, Van den Bergh R, et al. Applying the ICMJE authorship criteria to operational research in low-income countries: 
the need to engage programme managers and policy makers. Trop Med Int Health 2013;18:1025-8.

32 Smith E, Hunt M, Master Z. Authorship ethics in global health research partnerships between researchers from low or middle income countries and high income countries. BMC Med Ethics $2014 ; 15$.

33 Smith E, Master Z. Best practice to order authors in Multi/ Interdisciplinary health sciences research publications. Account Res 2017;24:243-67.

34 Davey Smith G, Munafò M, Kivimäki M. Swap outdated authorship listings for contributorship credit. Nature 2018;561:464.

35 Boshoff N. South-South research collaboration of countries in the southern African development community (SADC). Scientometrics 2010;84:481-503.

36 Fonseca BdePFe, Albuquerque PC, Noyons E, et al. South-South collaboration on HIV/AIDS prevention and treatment research: when birds of a feather rarely flock together. Global Health 2018;14.

37 Mêgnigbêto $\mathrm{E}$. International collaboration in scientific publishing Scientometrics 2013;96:761-83.

38 Onyancha OB, Maluleka JR. Knowledge production through collaborative research in sub-Saharan Africa: how much do countries contribute to each other's knowledge output and citation impact? Scientometrics 2011;87:315-36.

39 Toivanen $\mathrm{H}$, Ponomariov $\mathrm{B}$. African regional innovation systems: bibliometric analysis of research collaboration patterns 2005-2009. Scientometrics 2011;88:471-93.

40 Pouris $A$. The influence of collaboration in research priorities: the SADC case. S Afr J Sci 2017;113:11-12.

41 Confraria $\mathrm{H}$, Blanckenberg J, Swart C. The characteristics of highly cited researchers in Africa. Res Eval 2018;27:222-37.

42 Neff M. Quest for publication metrics undermines regional research. Nature 2018;554:169.

43 Geissler PW, Okwaro F. Developing world: discuss inequality. Nature 2014;513:303.

44 Kyamanywa P, Mukara KB, Sewankambo NK. Academic Collaborations: Do's and Don'ts. Curr Anesthesiol Rep 2017;7:15-22.

45 Walsh A, Brugha R, Byrne E. "The way the country has been carved up by researchers": ethics and power in north-south public health research. Int J Equity Health 2016;15. 